\title{
Households participation in waste management program in Mekong River Delta Vietnam: Parametric and non-parametric approaches
}

Tien Dung Khong ${ }^{*}$, Xuan Thi Dan Huynh ${ }^{2}$

School of Economics, Can Tho University, Vietnam ${ }^{1,2}$

ktdung@ctu.edu.vn ${ }^{1^{*}}$, htdxuan@ctu.edu.vn ${ }^{2}$

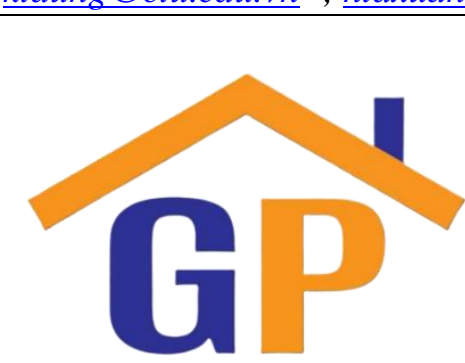

Article History

Received on 3 September 2021

$1^{\text {st }}$ Revision on 10 October 2021

$2^{\text {nd }}$ Revision on 17 October 2021

$3^{\text {rd }}$ Revision on 15 September 2021

$4^{\text {th }}$ Revision on 10 November 2021

Accepted on 29 November 2021

\begin{abstract}
Purpose: This study aims to estimate households' willingness to pay (WTP) in the Mekong River Delta for the improvement of solid waste (SW) management and identify factors influencing willingness to pay for the improvement program. Then, based on the results, this research proposed some policy implications for better SW management.
\end{abstract}

Research methodology: The research employed both Contingent Valuation Methodology - CVM employed parametric and nonparametric approaches to estimate WTP and Logit model to identify the determinants of WTP.

Results: The results from a random survey of 400 observations from 3 main cities in the Mekong River Delta (MRD) indicate that households' willingness to pay level is from 86,000 Vietnamese Dong (VND) to $110,000 \mathrm{VND} /$ month/household for the non-parametric and parametric approach, respectively (US $\$ 1$ was equal to 22,890 VND on June 30th, 2021). The results also determine the factors influencing the decision to pay for the program, including bid level, households who have already classified waste, households who intend to support the program, and households' income.

Limitations: In future research, survey areas should be expanded to other developing countries in order to compare and provide a base for proposing better waste management programs in developing countries.

Contribution: Future studies should apply both approaches to check the consistency of willingness to pay value elicited. Besides, in order to encourage households to participate in the waste classification program, the authorities need to raise awareness and encourage higher-income households to participate in advance.

Keywords: Contingent valuation method, Domestic waste, Waste classification

How to cite: Khong, T, D., and Huynh, X, T, D. (2022). Households participation in waste management program in Mekong River Delta Vietnam: Parametric and non-parametric approaches. Journal of Social, Humanity, and Education, 2(2), 101-113.

\section{Introduction}

Currently, the amount of solid waste (SW) generated from human daily activities as well as production activities is increasing. Therefore, the level of environmental pollution is increasingly serious. The "National Strategy on integrated solid waste management to 2025, with a vision to 2050" approved in the Vietnam Prime Minister's Decision No. 2149/QĐ-TTG has set out some specific goals. By 2025, it is expected that $90 \%$ of total urban SW generated will be collected and treated, of which $85 \%$ will be recycled, reused, energy generated, or converted to organic fertilizer. This requires a more advanced waste management system with more integrated solutions. In which, the 
classification of solid waste at the source is one of the important solutions that provide many benefits and implications in terms of economy, society, environment, resources. Over the past few years, the Mekong River Delta (MRD) has had an impressive economic growth rate but has also increased the amount of SW significantly, threatening the quality of life of the people and the sustainable development of the region. Specifically, the total volume of solid waste generated in this region is about 5,283 tons/day while the amount of solid waste collected per day is only 3,656 tons/day (Ministry of Natural Resources and Environment, 2019; 2020). Therefore, solid waste collection, transportation, and treatment are essential, albeit very costly. Currently, each household only pays about 20,000 $\mathrm{VND}^{1} /$ month for this. At this fee, the Government has to subsidy with a relatively large amount. This will be a burden on the State budget while households are responsible for generating a large amount of domestic waste on the principle that 'polluters pay'. Therefore, policymakers must consider the feasibility and willingness of people to participate in order to implement policy effectively. Therefore, the implementation of the project to estimate the people's willingness to pay for the quality improvement of SW management services is essential.

Thus, the implementation of the project of estimating the willingness to pay people for the improvement of the quality of MSW management services is essentially necessary. From there, as a scientific basis to propose solutions to implement solid waste management programs more effectively, especially in Vietnam and other developing countries.

\section{Literature review and hypothesis development}

Proper management of MSW improves environmental quality and public health. However, people have different preferences for MSW management programs in order to improve management capacity and reduce MSW quantity as well. Therefore, valuing these different preferences is complicated because preferences have no market value while non-market value is usually estimated using nonmarket valuation methods. The basic principle of these methods is willing to pay (WTP) or willing to accept (WTA) (Bateman et al., 2002; Moran, 1994).

However, finding an equivalent concept for environmental goods or services is very complicated

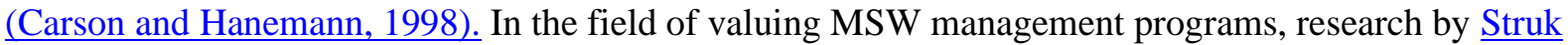
and Pojezdná (2019) employed the travel-cost method (TCM) and study Arimah (1996) used Hedonic Pricing Model (HPM) to estimate people's willingness to pay for the improvement of MSW management service quality. However, the author noted that the estimated value is only the use-value of this program. Thus, to be able to fully assess the value of non-market goods, the use of the reveal preference method is necessary.

The reveal preference approach includes the contingent valuation method (CVM) and the choice modeling (CM) (Aadland and Caplan, 2006) which are direct valuation methods with the assumption that individuals can reveal their real preference for environmental goods through their behavior in the hypothetical market (Hanley et al., 1998). Individuals were surveyed about their willingness to pay for environmental goods or their willingness to accept compensation for the loss of those goods. The main benefit of the preference statement method is that it can be used to price any goods and services and the data requirements are relatively low. Besides, the preference statement method is considered suitable when used to estimate indirect use-values, as well as non-use values of environmental goods (Becker and Freeman, 2009). This is the basis for prioritizing the application of the reveal preference approach in the evaluation studies of the MSW management program.

Previously, a number of studies have been carried out in developing countries that have shown that willingness to pay bid levels, age, income, household size, occupation, and education level affect the households' willingness to pay for solid waste management services (Rahji and Oloruntoba, 2009; Altaf and Deshazo, 1996; Niringiye and Omortor, 2010; Yusuf et al., 2007a; 2007b). Rahji and Oloruntoba (2009) applied a random pricing method (CVM) to predict the determinants of households' willingness to pay for solid waste management services in Ibadan, Nigeria. Research

${ }^{1}$ US\$1 was equal to 22,890 Vietnamese Dong (VND) on June 30th, 2021 
shows that a number of factors such as income, assets owned, occupation and payment amount affect willingness to pay. In the study by Altaf and Deshazo (1996) applied CVM to identify the needs of households for improved solid waste management in Gujranwala, Pakistan, and found that the amount of waste generated by households, household size, and age affect willingness to pay. Similarly, in the study by Niringiye and Omortor (2010) on the determinants of willingness to pay for solid waste management in Uganda, using CVM, the results indicated that age affects the willingness to pay. Yusuf et al., (2007a) also used CVM to estimate the economic value of improved household waste management in Oyo State, Nigeria having determined the cost of waste management services, age, education level, income, and household size affect willingness to pay. Other research also seeks ways to manage waste, however, only a qualitative approach has been employed (Silva and Toda (2020).In addition, when analyzing community participation in any public project implementation, objective information is necessary (Khong et al., 2020). These important issues have been confirmed and revealed in other sectors such as education (Shukla et al., 2021), miro finance (Akeny et al., 2020; Soleimani et al., 2021).

Therefore, this study is expected to contribute to the existing literature on the application of CVM in collecting information on the preferences of households willing to pay for MSW management services in rural areas in developing countries. In addition, the determined willingness to pay can also be used to determine the benefits of engaging private companies in residential waste management. The most interesting point is that the comparison between the two approaches is expected to increase the accuracy of the estimates of willingness to pay. Besides, in practical terms, the Mekong Delta is already facing the problem of how best to manage MSW. Currently, the government agency plays a supervisory role, while the private company is responsible for the collection and treatment of SW. Since there are only a few private companies involved in the provision of solid waste management services, these companies have little incentive to provide the service required in terms of quality by households. This study, therefore, provides information on people's willingness to pay for MSW management, which involves many private companies to improve the current MSW management situation in the MRD.

\section{Research methodology Data collection technique}

Research data of the research was collected by randomly interviewing 400 respondents who are residents in three big cities located in MRD Vietnam, including Can Tho city (Urban level 1), An Giang province (Urban level 2), and Ca Mau province (Urban level 3). Each respondent was asked if it was willing to implement the at-source SW separation program at a proposed price and the answer was "yes" or "no". In which, the number of observations is evenly distributed to three cities. In each city, the number of respondents to be interviewed was randomly distributed among wards. Thus, the analyzed data will have high reliability and be presentative for the population. According to the report of the Ministry of Natural Resources and Environment (2019), the level of urbanization is one of the most important factors that cause the amount of solid waste to increase sharply, so the criterion of stratified sampling is very suitable by using urban-type factor. In addition, based on pre-test interviews and expert focus group discussion, five different prices were selected for this study. Each price (bid) was interviewed by 80 respondents. Each respondent was asked if it was willing to implement the at-source SW separation program at a given price and the answer was "yes" or "no".

The specific scenario is developed as follows: The program of waste separation at the source is a program that requires domestic solid waste to be segregated at the emission source (household). The domestic solid waste collection and treatment system must be invested in a synchronous manner (for example, if domestic solid waste is classified into three groups by households, the collection and treatment system must ensure collected and disposed of 3 separate categories). The benefits of a waste separation program at source are: (1) saving on treatment costs; (2) environmental protection; (3) resource protection; (4) increase public awareness.

According to the calculation of the domestic waste collection and treatment unit, the cost for garbage collection and treatment is from $150,000 \mathrm{VND} /$ month/household. Currently, each household only 
pays about 20,000 VND/month for this. This fee is much lower than the actual fee that households have to pay because the Government is implementing a policy to compensate for losses. Assuming the Government removes this policy, each household has to pay the amount on the garbage bill from $150,000 \mathrm{VND} /$ month. But when households do the separation of waste at the source, the fee to pay for collection and treatment will be less than $150,000 \mathrm{VND} /$ month.

The WTP question was then asked:

Are you willing to contribute to reducing the cost of waste collection and treatment by accepting to participate in the waste separation program at the source?

The objective of the interview was to find out whether households in this area are willing to pay "20,000", " $50,000 ", " 80,000 "$, " $110,000 ", " 150,000 \mathrm{VND}$ " in order to reduce subsidies to the government through this improvement program.

\section{Data analysis method}

This study employed descriptive statistical methods to find out an overview of the socio-economic characteristics of the respondents and information related to the amount of waste generated and how it is treated in the study area. In addition, in order to obtain information on the financial contribution to the implementation of the waste separation program at the source, the study uses a contingent valuation method (CVM) to estimate the household's willingness to pay for the improvement of household solid waste management services.

Estimate WTP value using the non-parametric method:

The CVM method is based on the random utility theory of Luce (1959) and McFadden (1973) using the indirect utility function of households from the consumption of SW management services and has the following form:

$$
\mathrm{V}(\mathrm{p}, \mathrm{qi}, \mathrm{M}, \varepsilon)
$$

Where $\mathrm{p}$ is the price vector, $\mathrm{q}$ is the number of goods sold, $\mathrm{M}$ is income, and $\varepsilon$ is the random error. In case the quality of SW management service is improved, the utility function of the household will be:

$$
\mathrm{V}\left(\mathrm{q}_{1}, \mathrm{M}, \varepsilon\right) \geq \mathrm{V}\left(\mathrm{q}_{0}, \mathrm{M}, \varepsilon\right)
$$

The probability of a household choosing an improved SW management service is:

$$
\operatorname{Pr}[\text { Yes }]=\operatorname{Pr}\left[\mathrm{V}\left(\mathrm{q}_{1}, \mathrm{M}-\mathrm{t}_{\mathrm{k}}, \varepsilon_{1}\right) \geq \mathrm{V}\left(\mathrm{q}_{0}, \mathrm{M}, \varepsilon_{0}\right)\right]
$$

Assume the utility function is linear: $\mathrm{v}\left(\mathrm{q}_{\mathrm{i}}, \mathrm{M}\right)+\varepsilon_{\mathrm{i}}$

It is possible to write a formula for the probability that the choice Yes is

$$
\operatorname{Pr}[\text { Yes }]=\operatorname{Pr}\left[\mathrm{v}\left(\mathrm{q}_{1}, \mathrm{M}-\mathrm{t}_{\mathrm{k}},\right)-\mathrm{v}\left(\mathrm{q}_{0}, \mathrm{M}\right)+\varepsilon_{1}-\varepsilon_{0} \geq 0\right]
$$

The household will choose Yes when the sum of utility changes, $\Delta U=v\left(q_{1}, M-t_{k},\right)-v\left(q_{0}, M\right)$, and the difference of error, $\eta=\varepsilon 1-\varepsilon 0$, is large more than 0 . Probability can be written as

Based on probability theory, we have

$$
\operatorname{Pr}[\text { Yes }]=\operatorname{Pr}[\eta \geq-\Delta \mathrm{U}]
$$

$$
\operatorname{Pr}[\text { Yes }]=\operatorname{Pr}[\eta \geq-\Delta U]=1-F_{\eta}(-\Delta U)
$$

Where $F \eta$ is the probability density function (CDF) of $\eta$. To satisfy the condition of symmetric distribution, we have $\mathrm{F}(\mathrm{x})=1-\mathrm{F}(-\mathrm{x})$

It is assumed to have asymmetric distribution, we can write the probability as

$$
\operatorname{Pr}[\mathrm{Yes}]=\operatorname{F\eta }(\Delta \mathrm{U})
$$

The cumulative density function CDF gives the probability of the observations having an eigenvalue of $\Delta \mathrm{U}$. The probability density function PDF shows the probability of an observation with an eigenvalue of $\Delta \mathrm{U}$. These two functions have similarities in distributive properties. The relationship 
between these two functions is $F_{\eta}(\Delta U)=\int_{-\infty}^{\Delta U} f(x) d x$, where $f(x)$ is the probability density function. Thus the probability of observing the eigenvalues of $\Delta \mathrm{U}$ is also the area under the PDF curve.

The model is estimated to be a maximum likelihood. If $\mathrm{I}_{\mathrm{k}}$ represents the answer to the $\mathrm{k}_{\mathrm{th}}$ observation, with $\mathrm{I}_{\mathrm{k}}=1$ :

with $\mathrm{I}_{\mathrm{k}}=0$ :

$$
\operatorname{Pr}[\text { Yes }]=\operatorname{Pr}\left[\mathrm{I}_{\mathrm{k}}=1\right]=\operatorname{Pr}\left[\eta_{\mathrm{k}} \leq \Delta \mathrm{U}_{\mathrm{k}}\right]=\mathrm{F}_{\eta}\left(\Delta \mathrm{U}_{\mathrm{k}}\right)
$$

$$
\operatorname{Pr}[\mathrm{No}]=\operatorname{Pr}\left[\mathrm{I}_{\mathrm{k}}=0\right]=1-\operatorname{Pr}\left[\eta_{\mathrm{k}} \leq \Delta \mathrm{U}_{\mathrm{k}}\right]=1-\mathrm{F}_{\eta}\left(\Delta \mathrm{U}_{\mathrm{k}}\right)
$$

The likelihood function is written as:

$$
\left.\prod_{\mathrm{k}=1}^{\mathrm{N}} \operatorname{Pr}\left[\mathrm{I}_{\mathrm{k}}=1\right] \operatorname{Pr}\left[\mathrm{I}_{\mathrm{k}}=0\right]=\prod_{\mathrm{k}=1}^{\mathrm{N}}\left[F_{\eta}\left(\Delta \mathrm{U}_{\mathrm{k}}\right)\right]^{\mathrm{I}_{\mathrm{k}}}\left[1-F_{\mathrm{\eta}} \Delta \mathrm{U}_{\mathrm{k}}\right)\right]^{1-\mathrm{I}_{\mathrm{k}}}
$$

Where $\mathrm{N}$ is the number of observations. If we take the log rational function, we get the rational function as:

$$
\log \mathrm{L}=\sum_{\mathrm{k}=1}^{\mathrm{N}} \mathrm{I}_{\mathrm{k}} \ln \mathrm{F}_{\mathrm{\eta}}\left(\Delta \mathrm{U}_{\mathrm{k}}\right)+\left(1-\mathrm{I}_{\mathrm{k}}\right) \ln \left(1-\mathrm{F}_{\mathrm{\eta}}\left(\Delta \mathrm{U}_{\mathrm{k}}\right)\right)
$$

Estimate WTP value using the parametric method:

From the utility function estimated above, to measure the willingness to pay level, the parametric method was also employed to estimate the mean and median of the willingness to pay level based on the coefficient of constant coefficient of the regression model and the coefficient of bid (price) variable, together with the coefficients of variables on respondents attitudes and other socio-economic characteristics. Logit model with the coefficient estimation formula is presented as follows:

$$
\begin{gathered}
P_{i}=F\left(x_{i}^{\prime} \beta\right)=\frac{e^{x_{i}^{\prime} \beta}}{1+e^{x_{i}^{\prime} \beta}} \\
\text { Where } x_{i}^{\prime} \beta=\beta_{0}+\beta_{1} x_{1}+\beta_{2} x_{2}+\beta_{3} x_{3}+\beta_{4} x_{4}+\beta_{5} x_{5}+\beta_{6} x_{6}+\beta_{7} D_{1}+\beta_{8} D_{2}
\end{gathered}
$$

The dependent variable (Y) is the probability of agreeing to pay for SW service fees. This variable has two values, $Y=1$, if the respondent agrees to pay, and $Y=0$, if the respondent is not willing to pay. The independent variables include Bid (X1), which is the monthly fee each household pays for SW management services. These fees are suggested based on the fees for unsubsidized SW management services from the government and pilot interviews. TUPHANLOAI (D1) is a dummy variable that takes two values, D1 = 1 if the household does its solid waste classification before it is collected by a sanitation worker, and D1 $=0$, if the household does not self-classify SW; TUOI (X2) is the age of the respondents (unit: years). GTINHNAM (D2) is the dummy variable taking two values, D2 $=1$ if the respondent's gender is male, and D2 $=0$, if the respondent's gender is female. TDHV (X3) is the number of years in the school of the respondents (unit: year). Those who attend higher school tend to fully understand the benefits of SW management service and the harms of SW, and thus tend to pay for it. TNHAP3TRIEU (D3) is the dummy variable that takes two values, D3 $=1$, if the respondent's monthly income is less than 3 million VND, and D3 $=0$, if the respondent's monthly income is 3 million VND or more. TNHAP3-9TRIEU (D4) is a dummy variable that takes two values, D4 $=1$, if the respondent's monthly income is from 3 million VND to less than 9 million VND, and D4 $=0$, if the respondent's monthly income is not from 3 million VND to under 9 million VND. One of the purposes of waste management is to provide a clean environment and help improve environmental quality. The demand theory for environmental goods assumes that the higher the income, the higher demand for environmental quality (Lewis and Tietenberg, 2010).

The non-parametric method is also applied as a basis for comparison with the parametric method, in particular, the average highest willingness to pay is calculated by the formula: 


$$
\bar{C}=\sum_{j=1}^{J} \hat{S}\left(B_{j}\right)\left[B_{j}-B_{j-1}\right]
$$

Where: Bjvà $\mathrm{Bj}-1$ are the fees, the survivor function $\hat{S}\left(B_{j}\right)$ of each fee $\mathrm{Bj}$ is $\mathrm{Bj}$ là: $\hat{S}\left(B_{j}\right)=\frac{n_{j}}{N_{j}} j=0$ to $J, \mathrm{~N}$ is the number of respondents in the sample, $\mathrm{N}_{\mathrm{j}}$ is the number of respondents corresponding to the fee $B_{j}, n_{j}$ is the number of respondents who agree to pay at $B_{j}$.

Thus, both parametric and non-parametric methods were also applied as a basis for comparison and validity, increasing the certainty of the analysis results and as a scientific basis for proposing appropriate management policies.

\section{Results and discussions Respondent characteristics}

The results reveal that there are $31.2 \%$ male respondents and $68.8 \%$ female respondents. The average age of the respondents is 52.23 years old. Out of 400 respondents, $1 \%$ of respondents did not go to school, $25 \%$ of respondents had level 2, 30\% of respondents had level 3 and $11 \%$ of respondents had above. Most of the respondents have an average income of less than 7 million VND / month, accounting for about $85 \%$ of the total number of respondents. In the Mekong Delta currently, although the local government has not implemented massively the program to classify SW at source, survey results show that $67.55 \%$ of households sell scrap, or in other words, they have self-classify SW before it is collected. This is a good signal to implement SW classification program to improve the quality of SW management services. Besides, 32.5\% of households still have not sold scrap yet. Among the reasons for scrap classification and sale, it is interesting that people are already aware of the importance of environmental protection for their actions, besides, this is also a source of their income, although this amount is not too much. On the contrary, those who do not sort and sell scrap for the reason that the selling amount is too small, notably, still some people do not pay much attention to this classification.

\section{Analysis results on households' awareness about recycling and selling scrap}

In the Mekong River Delta currently, although localities have not implemented the program of classifying MSW at source, about $65 \%$ of households have conducted self-classification before it is collected. In fact, recycling is one of the effective measures to reduce the amount of MSW released into the environment, thereby limiting the negative effects of this on the living environment. However, besides the households that have implemented the recycling act, there are still $35 \%$ of the households that have not yet implemented the recycling activity. Households with and without scrap collection were asked to reveal their reasons. These reasons are shown in Figure 1 below.

\section{Household group with recycling activity}

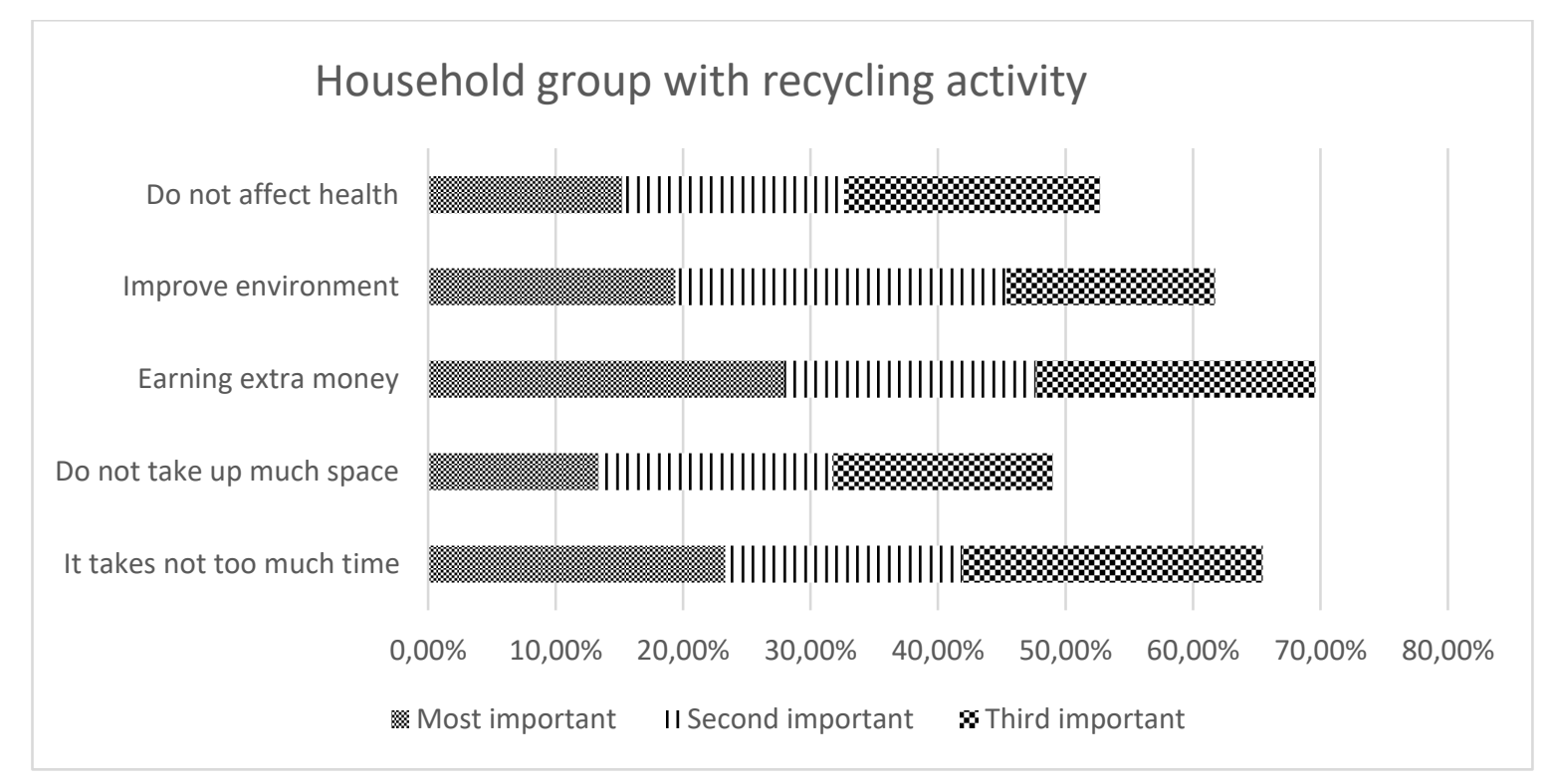




\section{Household group without recycling activity}

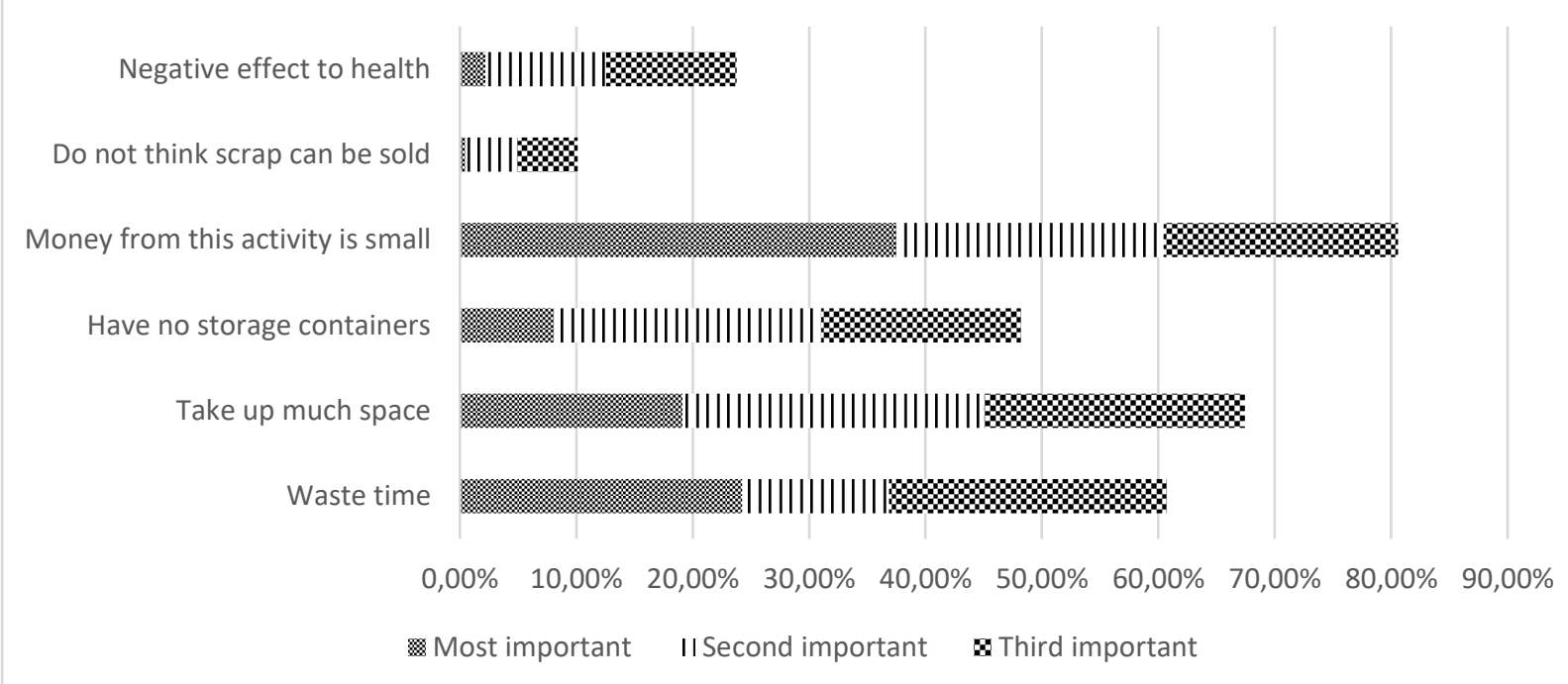

Figure 1. Reasons affecting the implementation of households' recycling behavior Source: Survey data, 2020

The reason that $65 \%$ of households practice recycling is that the income from this activity is also a motivation for them to do this. This is one of the reasons many respondents choose as the most important reason for them to carry out the classification, collection, storage, and sale of scrap. In addition, according to them, sorting and storing recyclable components from MSW is not a timeconsuming activity. If people know how to arrange, the amount of stored scrap does not take up much of the house. At the same time, the storage of scrap does not cause pollution if the scraps are cleaned before being stored. In addition, some respondents carry out scrap collection because this activity contributes to environmental protection in the long term.

Contrary to the opinions of households group with scrap collection, 35\% of households that do not practice recycling believe that although sorting and collecting MSW takes a lot of time and space for the amount of scrap stored in a largely residential area, the amount from the sale of scrap is not much. These reasons can be the basis for proposing solutions to improve the recycling activities of households, thereby improving the quality of the recycling-oriented MSW management system in the MRD.

The findings also reveal that the average household sells scrap about once a month, the types of scrap traded are quite diverse. However, because scrap is the components recovered from the MSW, depending on the type of scrap that accounts for more or less in the MSW, the amount collected and traded is more or less. For example, compared with other components, plastic and paper account for a higher proportion and are often generated in household MSW, so the amount of scrap in the plastic and paper group is higher than the other groups such as metal, glass, crystal, and fabric. This data is consistent with the findings from the World Bank (2018), in which the proportion of plastic components is $3.4 \%-10.6 \%$, paper components are $3.3 \%-6.6 \%$, while the metal part is $1.4 \%-4.9 \%$, and glass composition $0.5 \%-2.0 \%$.

It is also worth noting that the recycling rate calculated from this research is at $2.9 \%$ while the potential recycling rate indicated by households' opinions is around $22.99 \%$. In other words, households themselves are also aware that MSW can be recycled up to $22.99 \%$. This point and the reasons stated in Figure 1 are the basis to help come up with measures to improve the recycling rate of 
MSW in households according to the objectives of the National Strategy on Improving the Recycling Rate in Vietnam. In other words, the proposed policy, if implemented, will have a great impact on reducing the current environmental pollution in the MRD.

\section{The willingness to pay for $S W$ management services in the Mekong River Delta}

Again, the data shows that a total of $66.75 \%$ of the respondents agree to pay for the SW management service and that $33.25 \%$ of the respondents do not agree to pay for this service. This level is relatively high. Specifically, at the fee of 20,000 VND / month, $93.75 \%$ of the respondents agreed to pay, only $6.25 \%$ of the respondents did not agree to pay. When the fee increased to 50,000 VND / month, 77.5\% agreed to pay. The number of people who agreed to pay decreased to $68.75 \%$ at the fee of 80,000 VND / month. This willingness to pay rate continued to decrease to $53.75 \%$ when the fee increased to $110,000 \mathrm{VND} /$ month. At the highest fee of 130,000 VND / month, only $40 \%$ of respondents were willing to pay. Therefore, the number of respondents who are willing to pay decreases gradually when the fee for SW management services increases. This result is completely consistent with the economic theory of the demand curve. Based on the estimation method of Kaplan - Meier - Turnbull (KMT estimator) (Bateman et al., 2002; Bishop et al., 1995; Carson, 2004), the average value of willingness to pay for the quality improvement of SW management services is $86,750 \mathrm{VND} / \mathrm{month} /$ household.

Table 1. The proportion of willingness to pay for SW management services

\begin{tabular}{crrrrr}
\hline Bid level & \multirow{2}{*}{$\begin{array}{c}\text { Number of } \\
\text { VND/month) }\end{array}$} & \multicolumn{2}{c}{ Willing to pay } & \multicolumn{2}{c}{ Unwilling to pay } \\
\cline { 3 - 6 } & & $\begin{array}{c}\text { Number of } \\
\text { observations }\end{array}$ & $\begin{array}{c}\text { Percentage } \\
(\%)\end{array}$ & $\begin{array}{c}\text { Number of } \\
\text { observations }\end{array}$ & $\begin{array}{c}\text { Percentage } \\
(\%)\end{array}$ \\
\hline 20.000 & 80 & 75 & 93,75 & 5 & 6,25 \\
50.000 & 80 & 62 & 77,50 & 18 & 22,50 \\
80.000 & 80 & 55 & 68,75 & 25 & 31,25 \\
110.000 & 80 & 43 & 53,75 & 37 & 46,25 \\
130.000 & 80 & 32 & 40,00 & 48 & 60,00 \\
\hline Total & 400 & 267 & 66,75 & 133 & 33,25 \\
\hline
\end{tabular}

Source: Survey data, 2020

Based on the estimation method of Kaplan - Meier - Turnbull (KMT estimator)(Bateman et al., 2002; Bishop et al., 1995; Carson, 2004), the average value of willingness to pay for the quality improvement of MSW management services is $86,750 \mathrm{VND} / \mathrm{month} /$ household (Figure 1). This is the average price that the respondents are willing to pay for the improvement program in the survey. In fact, In Ho Chi Minh City -other big cities in Vietnam, from 2020 will apply a fee of about 50,000 VND/household/month (Ministry of Natural Resources and Environment, 2020) when households perform waste classification. Thus, the WTP level of people in this survey is quite high compared to the price in Ho Chi Minh City applied. This shows that people in this area are increasingly concerned about the environment in general and domestic waste in particular. In addition, the estimated results show that the number of respondents agreeing to pay gradually decreases as the fee of MSW management services increases. This result is completely consistent with the economic theory of the demand curve (Gravelle, 2004). 


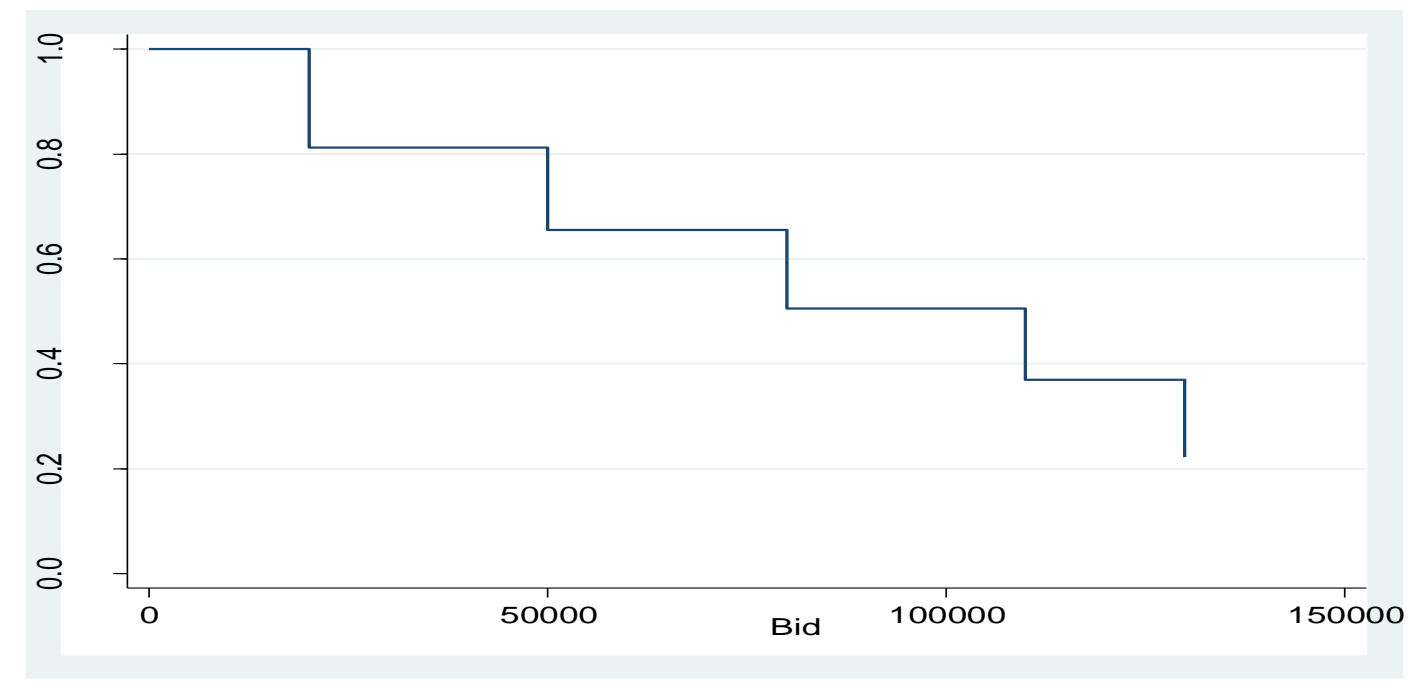

Figure 2. The proportion of respondents agreeing to pay for improved MSW management services as estimated by Kaplan-Meier-Turnbull (KMT estimator)

Source: Survey data, 2020

Table 2 presents the Logit model results for the 2 models, model 1 estimates the willingness to pay with only 1 independent variable Bid, and model 2 estimates the willingness to pay with independent variables including the socioeconomic characteristics of respondents, to consider the effect of these factors on willingness to pay. The analytical results show that the correct prediction percentage of model 1 is $70.75 \%$ and model 2 is $72.31 \%$, so it can be assessed that the correct prediction ability of both is quite appropriate.

Table 2. The determinants of households willing to pay for SW management system

\begin{tabular}{lrr}
\hline \multicolumn{1}{c}{ Variable } & \multicolumn{2}{c}{ Coefficients } \\
\cline { 2 - 3 } Constant & \multicolumn{1}{c}{ Model 1 } & \multicolumn{1}{c}{ Model 2 } \\
Bid & $1,642397^{* * * *}$ & $-0,0000157^{* * * *}$ \\
TUPHANLOAI & $-0,0000145^{* * * *}$ & $0,5328441^{* * *}$ \\
TUOI & & $-0,0000621$ \\
GTINHNAM & & 0,1463227 \\
TDHV & & 0,0137271 \\
TNHAP3TRIEU & & $-0,9621202^{* * *}$ \\
TNHAP3-9TRIEU & & $-0,9342411^{* * *}$ \\
\hline & Log likelihood $=-221,06084$ & Log likelihood $=-203,0551$ \\
& LR chi2 $(1)=66,63$ & LR chi $2(8)=90,37$ \\
& Prob $>$ chi2 $=0,0000$ & Prob $>$ chi $2=0,0000$ \\
& Pseudo R2 $=0,131$ & Pseudo R2 $=0,1820$ \\
& Number of observations: 400 & Number of observations: 390 \\
\hline
\end{tabular}

Source: Data survey, 2020

Note: $(*)=$ statistically significance at $10 \%,(* *)=$ statistically significance at $5 \%,(* * *)=$ statistically significance at $1 \%$

Besides, the regression results also show that the variable Bid is statistically significant at $1 \%$ in both models and has a negative sign, which means that the higher fee for SW management services, the lower probability of willingness to pay. In addition, the results from model 2 also show that when the respondent performs the SW classification at source and supports the implementation of the SW classification program at source, the probability of agreeing to pay for SW management services be improved higher. Compared to the control group, respondents with an income of 9 million VND / month or more, earning less than 3 million VND / month, and respondents earning from 3 million 
VND / month to less than 9 million VND / month have a probability agree to lower payments for SW management. In other words, the higher income the respondent has, the higher the probability of agreeing to pay for the quality improvement of SW management services. This result is consistent with previous studies such as Rahji and Oloruntoba (2009),Pek and Othman (2010), Altaf and Deshazo (1996), Niringiye and Omortor (2010), Yusuf et al (2007b), and Niringiye (2010). From the Logit model, the estimated results according to the parametric method show that the average WTP value of the people for the improvement of MSW management service is $110,000 \mathrm{VND} / \mathrm{month} /$ household and ranges from $102,663 \mathrm{VND} / \mathrm{month} /$ household to 127,337 $\mathrm{VND} / \mathrm{month} /$ household (at the significant level of 1\%). In addition, the analysis results of model 2 also revealed similar results.

Table 3. Estimated willingness to pay level by the parametric approach

\begin{tabular}{|c|c|r|r|r|r|}
\hline \multicolumn{2}{|c|}{ Item } & WTP & \multicolumn{1}{|c|}{ Lower } & \multicolumn{1}{|c|}{ Upper } & \multicolumn{1}{|c|}{ ASL } \\
\hline \multirow{2}{*}{ Mean/median } & Model 1 & 110.000 & 102.663 & 127.337 & 0,000 \\
\cline { 2 - 6 } & Model 2 & 110.000 & 103.022 & 125.889 & 0,0000 \\
\hline
\end{tabular}

Note: ASL, significance level for hypothesis testing: $H 0: W T P<=0, H 1:$ WTP $>0$

\section{Summary of findings}

In summary, as indicated, this study is one of the first research in the Mekong River Delta to compare the willingness to pay for at-source solid waste management programs by parametric and nonparametric approaches. Our findings indicate that the majority of respondents agree with this suggestion program. The WTP values revealed from the two approaches are 86,000VND and $110,000 \mathrm{VND}$, respectively. In addition, the main reasons why households do not want to participate in MSW classification are that it takes a lot of time, there is not enough storage space and they think this activity does not bring sufficient income. Therefore, this will be a waste of time for them. However, contrary to this finding from households without recycling activity, it is interesting from the household with recycling activity is that this research finds the opposite in their perception when they identify the reasons for participating in MSW classification including creating more income, do not spend too much time, especially contributing to environmental protection and do not affect health. Therefore, based on the analysis results mentioned here, this research then proposes solutions and recommendations in the following sections.

\section{Conclusion}

Briefly, this study employed two approaches simultaneously to estimate the level of payment for improved MSW management services by the non-parametric method (estimate by Kaplan-MeierTurnbull - KMT estimator) and the parametric method (estimated from the Logit model). Research results show that people in urban areas of the MRD are willing to pay to improve SW management services. Specifically, the results show that the price people are willing to pay to improve the SW management program is about 86,000 VND for the non-parametric method and 110,000 VND for the parametric method. The differences between the two methods are relatively consistent and reliable because the parametric approach includes the households attributes into the WTP level elicited. In other words, the non-parametric method is calculated based on the percentage of respondents and the price that agrees with the hypothetical situation given. Meanwhile, the parametric method also considers the influence of socio-economic and demographic factors including age, sex, education level, self-classifying behavior. Therefore, this combined result can be used for policymakers and authorities to consider the price in order to establish the program within the allowable range from 86,000 VND (lower limit) to 110,000 VND (upper limit). Based on this result, the author proposes that further studies should use both methods to ensure the reliability of the estimate and propose a more appropriate policy.

In addition, the respondents who have implemented the classification and supported the classification program tend to pay more, on the other hand, the households with higher income also tend to be more supportive. Thus, these results are a good signal in providing information on people's acceptance and support of SW management. 
In addition, the most important thing when implementing the program is that the management agencies need to strengthen supporting programs to raise people's awareness in environmental protection through the classification of solid waste at the source. Content of supporting programs may include education on environmental sanitation, the benefits of solid waste segregation at source for the community, active dissemination of laws and regulations issued by central and local authorities related to solid waste management, handling regulations on cases of violations of the law on environment, these contents should be integrated into local meeting programs and information posted at the People's Committees of provinces, communes, and towns in the MRD area. In addition, these awareness-raising activities should focus on households with higher incomes and already actively participating in environmental-related activities in the locality. These will be the objects that have a strong impact on other target groups, from which the spread of program implementation will be more effective. In addition, the results of expert interviews and field surveys also show that the capacity of relevant managers is limited, so the government needs to coordinate with training institutes. Finally, the People's Committees of the provinces and cities in the region should thoroughly and actively guide the application of waste segregation at source in their respective management areas as well as invest financial and material resources to implement the program effectively.

Based on the research results on the rate of willingness to participate in the program and the willingness to contribute price, policymakers in the region need to deploy to local governments at all levels to review and issue unit prices in order to collect, transport, and treat waste to suit the socioeconomic development conditions and circumstances of each region (according to the level of urbanization). The collection units should invest in standard collection equipment, modern means of transport suitable to the current collection situation in parallel with fully equipping workers with protective equipment to ensure long-term benefits and health for those directly involved in the program.

\section{Recommendations}

Research results reveal that the significant determinants that increase people's willingness to pay are their previous experience of recycling activity and bid level. The probability of willingness to pay is increased if they have participated in recycling activity before and, therefore realize the importance of this activity. Besides households' income, it is one of the factors that should be considered and focused on by policymakers when implementing solutions to reduce emissions. Thus, when implementing the program, it is necessary to focus on these two factors of the respondents to increase the willingness to pay of the households. However, besides $67 \%$ of respondents willing to take part in the program, there are still 33\% who do not support the classification of solid waste program. So, it is necessary to propose solutions in order to increase the rate of support for the classification of MSW at source as well as participating in the program to improve the quality of waste management services of households. Finally, time consumption and income from this activity are some of the reasons leading to households' unwilling to pay for MSW classification at the source. About $70 \%$ of households do not support implementing program because it is very time-consuming, affecting their work and life, and more than $80 \%$ of those who do not practice this behavior think that income from this activity is too small. Therefore, local authorities need to issue guidance documents and encourage people to do more MSW classification. Besides, because of the daily habits, households often do not classify MSW but only leave MSW in the form of a mixture. Therefore, there is a need for coordination between relevant departments to provide solid waste separation bins with clear and distinguishable colors and symbols. There is also a need to provide propaganda and recommendations activities to help people, when looking at the pictures and diagrams mentioned about the classification of MSW, it will be easier to understand and make it easier for them to implement.

\section{Limitations and study forward}

In future research, survey areas should be expanded to other developing countries in order to compare and propose waste management programs in developing countries. In addition, the local authorities should first implement the waste management proposed in this research in some areas. Then, an evaluation analysis by comparing before and after should be conducted to elicit the effectiveness of 
the program, it is a guarantee for the large-scale program to be implemented successfully. Households' perception about this program should also be conducted in the future to identify the objective information to create more motivations for this program. Finally, since gender issue is important for any public policy implementation (Amoding \& Mwesigwa, 2021), household analysis stratified by gender should also be included.

\section{Acknowledgment}

This study is funded in part by the Can Tho University Improvement Project VN14-P6, supported by a Japanese ODA loan

\section{References}

Aadland, D., \& Caplan, A. J. (2006). Cheap talk reconsidered: New evidence from CVM. Journal of Economic Behavior \& Organization, 60(4), 562-578.

Altaf, M. A., \&Deshazo, J. R. (1996). Household demand for improved solid waste management: A case study of Gujranwala, Pakistan. World Development, 24(5), 857-868.

Amoding, M., \&Mwesigwa, D. (2021). Gender equality and the effectiveness of primary education in Katosi town council, Mukono district in central Uganda. Journal of Social, Humanity, and Education, 1(2), 133-142. https://doi.org/10.35912/jshe.v1i2.434

Akeny, E., \&Mwesigwa, D. (2021). Personal savings and household investments: a cohort study among primary school teachers. Annals of Management and Organization Research, 1(4), 261270. https://doi.org/10.35912/amor.v1i4.468

Arimah, B. C. (1996). Willingness to pay for improved environmental sanitation in a Nigerian City. Journal of Environmental Management, 48(2), 127-138.

Bateman, I. J., Carson, R. T., Day, B., Hanemann, M., Hanley, N., Hett, T., \&Sugden, R. (2002). Economic valuation with stated preference techniques: a manual. Economic valuation with stated preference techniques: a manual.

Bishop RC, Champ PA, Mullarkey DJ. (1995). Contingent valuation. In: Bromley DW (ed) The handbook of environmental economics. Blackwell Publishers, Cambridge.

Becker, N., \& Freeman, S. (2009). The economic value of old-growth trees in Israel. Forest Policy and Economics, 11(8), 608-615.

Carson R .(2004). Contingent valuation: a comprehensive bibliography and history. Edward Elgar, Cheltenham/Northampton.

Carson, R., Flores, N. E., \&Hanemann, W. M. (1998). Sequencing and valuing public goods. Journal of Environmental Economics and Management, 36(3), 314-323.

Gravelle H, Rees P. (2004). Micro-economics. Pearson Education Limited, England.

Hanley, N., Wright, R. E., \&Adamowicz, V. (1998). Using choice experiments to value the environment. Environmental and resource economics, 11(3), 413-428.

Khong, T. D., Loch, A., \& Young, M. D. (2020). Perceptions and responses to rising salinity intrusion in the Mekong River Delta: What drives a long-term community-based strategy?. Science of The Total Environment, 711, 134759.

Lewis, L., \&Tietenberg, T. H. (2019). Environmental economics and policy. Routledge.

Luce, R. D. (1959). Individual choice behavior.

McFadden, D. (1973). Conditional logit analysis of qualitative choice behavior.

Ministry of Natural Resources and Environment. (2019). Report on the state of the national environment 2018.

Ministry of Natural Resources and Environment. (2020). Report on the state of the national environment 2019.

Moran, D. (1994). Contingent valuation and biodiversity: measuring the user surplus of Kenyan protected areas. Biodiversity \& Conservation, 3(8), 663-684.

Niringiye A, Omortor DG. (2010). Determinants of willingness to pay for solid waste management in Kampala city. CurrRes J Econ Theory 2(3):119-122 Lewis, L., \&Tietenberg, T. H. (2019). Environmental economics and policy. Routledge.

Niringiye, A. (2010). Determinants of willingness to pay for solid waste management in Kampala City. Current Research Journal of Economic Theory, 2(3), 119-122.

Pek, C. K., \& Othman, J. (2010). Household demand for solid waste disposal options in Malaysia. 
Shukla, N., Prasad, S. K., \&Itam, U. (2021). Exploring the key behavioural, functional and strategic competencies in Indian management education. International Journal of Financial, Accounting, and Management, 3(1), 65-82. https://doi.org/10.35912/ijfam.v3i1.423

Soleimani, E., Dehyadegari, M., \&Gerami, H. Z. (2021). Application of hierarchical method and fuzzy AHP-TOPSIS method for multi-criteria decision making in financing. Annals of Management and Organization Research, 1(4), 307-317. https://doi.org/10.35912/amor.v1i4.573

Silva, L. M. D., Nursalam, \& Toda, H. (2020). Policy implementation of local governments in waste management in Dili City, Timor Leste. Journal of Governance and Accountability Studies, 1(1), 1-13. https://doi.org/10.35912/jgas.v1i1.343

Struk, M., \&Pojezdná, M. (2019). Non-market value of waste separation from municipal perspective. In Proceedings of 17th International Waste Management and Landfill Symposium (Sardinia 2019).

Rahji, M. A. Y., \&Oloruntoba, E. O. (2009). Determinants of households' willingness to pay for private solid waste management services in Ibadan, Nigeria. Waste management \& research, 27(10), 961-965.

Vietnam Prime Minister. (2009, December). Decision No. 2149/QĐ-TTG of the Vietnam Prime Minister approving the national strategy on integrated solid waste management to 2025, with a vision to 2050. Retrieved from http://moc.gov.vn/vn/Pages/ChiTietVanBan.aspx?vID=712\&TypeVB=0

Yusuf SA, Salimonu KK, Ojo OT. (2007a). Determinants of willingness to pay for improved household waste management in Oyo State, Nigeria. Res J Appl Sci 2(3):233-239.

Yusuf, S. A., Ojo, O. T., \&Salimonu, K. K. (2007b). Households' willingness to pay for improved solid waste management in Ibadan North local government area of Oyo state, Nigeria. Journal of Environmental Extension, 6, 57-63. 